\title{
Manufacturing of Vortex Granulators: Simulation of the Vortex Fluidized Bed Functioning under the Disperse Phase Interaction in the Constrained Motion
}

\author{
Artem Artyukhov ${ }^{1}$, Jan Krmela ${ }^{2,3}$, Vladimíra Krmelová ${ }^{4}$ \\ ${ }^{1}$ Faculty of Technical Systems and Energy Efficient Technologies, Sumy State University. RymskogoKorsakova \\ st.,2, 40007, Sumy. Ukraine. E-mail: a.artyukhov@pohnp.sumdu.edu.ua \\ ${ }^{2}$ Faculty of Industrial Technologies in Púchov, Alexander Dubček University of Trenčín. I. Krasku 491/30, 02001 \\ Púchov. Slovak Republic. E-mail: jan.krmela@tnuni.sk \\ ${ }^{3}$ Faculty of Transport Engineering, University of Pardubice. Studentská 95, 53210 Pardubice. Czech Republic. \\ E-mail: jan.krmela@upce.cz \\ ${ }^{4}$ Faculty of Industrial Technologies in Púchov, Alexander Dubček University of Trenčín. I. Krasku 491/30, 02001 \\ Púchov. Slovak Republic. E-mail: vladimira.krmelova@tnuni.sk
}

The work presents the computer simulation results describing the motion of the interacting particles in a vortex fluidized bed (the constrained motion). The data obtained reveal the peculiar features of the polydisperse system motion in the apparatuses with the variable cross-section of the workspace. The empirical coefficient determining the residence time of a particle in the vortex fluidized bed was calculated. An algorithm of the residence time calculations for a particle in the vortex fluidized bed under the constrained motion is developed. The results of computer simulation were a part of engineering (technological and constructive) algorithm of calculation for the future manufacturing of granulator's industrial sample.

Keywords: Computer Modeling, Vortex Granulator, Constrained Motion, Optimization

\section{Introduction}

Simulation of the particles and their ensembles motion in the heat and mass exchange apparatuses for processing in the "gas-solid" system is an important element in the general algorithm of the target process calculations. An optimal residence time of the disperse phase in the workspace depends on the accuracy of calculations. The fact that free motion of a particle in an industrial apparatus is observed only in the small volumes of the disperse phase in the two-phase system $(\psi<0.1)$ makes the calculations more complicated. In such a case, the distance between particles eliminates collisions and mutual influences on each other. If $\psi>$ 0.1 , the distances between the particles' surfaces (the sizes of paths) become less than their diameter, and a particle cannot freely jump between the two others [1, 2]. In such a case, the fact of particle collisions must be taken into consideration. The collision of particles in the two-phase system can also occur when the disperse phase consists of the polydisperse particles or particles of different density [3]. Moreover, the particle motion in the gas medium creates the field of velocity and pressure. In their turn, other particles, constituting the so-called ensemble and the walls of a granulator have a hydrodynamic effect on the particle.

The authors [1-5] suggest taking into account the constrained mode of motion when we perform calcu- lations of the particle's residence time in the workspace of the apparatus

$$
\tau_{c m}=\tau f_{e \tau}(\psi)
$$

where $\tau_{c m^{-}}$a time of the constrained motion of particles in the disperse phase; $\tau$ - a time of a single particle motion; $f_{e \tau}(\psi)$ - an empirical influence function of the constraint conditions on the residence time of a particle in the workspace.

The function $f_{e \tau}(\psi)$ is:

$$
f_{e \tau}(\psi)=(1-\psi)^{-m}
$$

where $m$ - an empirical measure of the stage (a constraint coefficient for the time calculations).

At present, there are no literature data on the determination of the empirical measure $m$ in the formula (2) for a vortex fluidized bed. A task to determine the empirical measures is complicated due to the presence of separate zones at difference heights with different intensity and variable prevailing directions of the particle motion.

The aim here is to determine the peculiar features of the particle ensemble motion in the workspace of a vortex granulator in a constrained mode and to define the empirical measure $\mathrm{m}$ for a vortex fluidized bed.

Computer simulation is one of the most productive methods for studying the structure of flows, properties of materials, etc. $[6,7]$. 
The analysis of the previous works on the simulation of the two-phase flows, consisting of gas as a disperse phase and disperse particles, has proved that one of the most promising methods of calculating the particles motion is the so-called the trajectory method [8]. The authors [9] conclude that the simulation of the constrained motion of particles with a big diameter $(0.5-5 \mathrm{~mm})$ may be based on the Lagrangian method for the force analysis of the particle motion with the use of the differential equations of motion, which has been applied in the description of the hydrodynamic condition of the disperse phase motion in the workspace of the granulator [8-10]. Herewith, the application of the trajectory method for the particles motion in the workspace of the granulator is complicated by the following:

- the polydispersity of the system;

- the constrained motion of granules in the vortex granulator.

In this regard, the trajectory method with a high accuracy of the results obtained can be applied only with the software, which enables us to export the theoretic model of the single particle motion and to take into account the constraint ratio of the flow.

\section{Visualization of results and discussion}

The calculations of the hydrodynamics of the polydisperse system motion within the vortex fluidized bed are based on the author's mathematical model [10-15].

In this work, the software product ANSYS FLUENT was used to export the original mathematical model, to calculate the trajectory of the granules' motion and the distribution law of the polydisperse system in the workspace of the granulator, taking into account the concentration of granules (the constraint ratio of the flow).

Figs. $1-3$ visualize the results of modelling the motion of the polydisperse system of granules under the change of the opening angle of the cone in the vortex granulator (a relative content of granules in the workspace $\psi=0.25)$.

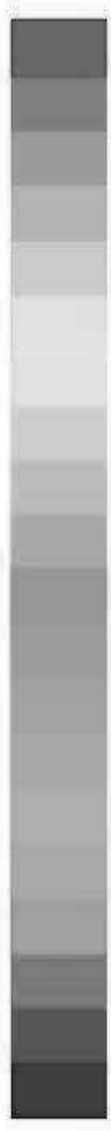
$3.00 \mathrm{e}-03$
$2.90 \mathrm{e}-03$
$2.80 \mathrm{e}-03$
$2.70 \mathrm{e}-03$
$2.60 \mathrm{e}-03$
$2.50 \mathrm{e}-03$
$2.40 \mathrm{e}-03$
$2.30 \mathrm{e}-03$
$2.20 \mathrm{e}-03$
$2.10 \mathrm{e}-03$
$2.00 \mathrm{e}-03$
$1.90 \mathrm{e}-03$
$1.80 \mathrm{e}-03$
$1.70 \mathrm{e}-03$
$1.60 \mathrm{e}-03$
$1.50 \mathrm{e}-03$
$140 \mathrm{e}-03$
$1.30 \mathrm{e}-03$
$1.20 \mathrm{e}-03$
$1.10 \mathrm{e}-03$
$1.00 \mathrm{e}-03$
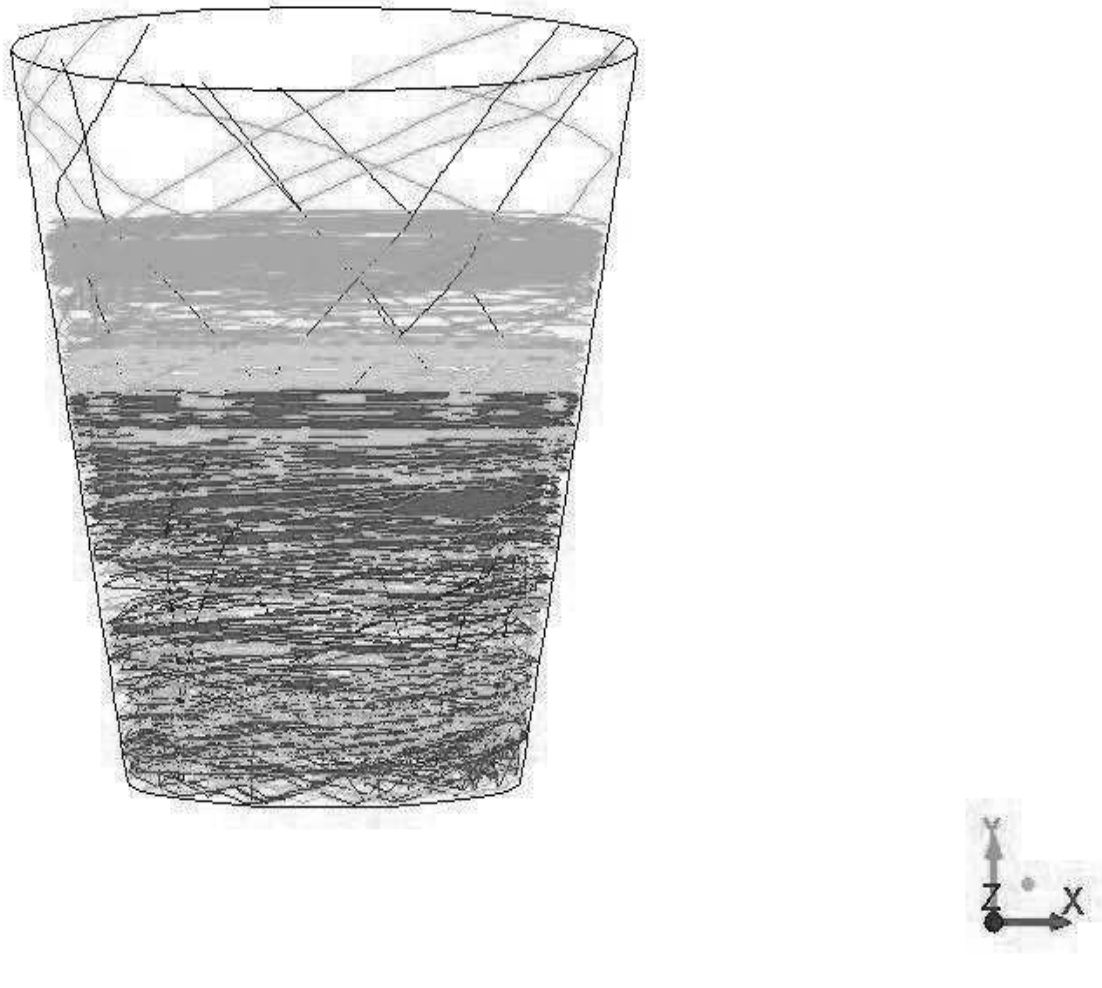

Particle Traces Colored by Particle Diameter (m)

ANSYS Fluent 15.0 ( $3 \mathrm{~d}$, pbns, rke)

Fig. 1 The trajectory of the polydisperse granules motion under the opening angle of the cone $10^{\circ}$ (the constrained motion of granules) 


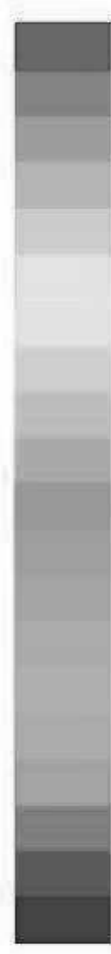
3.00e-03
$2.90 e-03$
2. $80 \mathrm{e}-03$
$2.70 \mathrm{e}-03$
$2.60 \mathrm{e}-03$
$2.50 e-03$
$2.40 \mathrm{e}-03$
$2.30 \mathrm{e}-03$
2. $20 \mathrm{e}-03$
2. 10e-03
$2.00 \mathrm{e}-03$
$1.90 \mathrm{e}-03$
$1.80 \mathrm{e}-03$
$1.70 e-03$
$1.60 \mathrm{e}-03$
$1.50 e-03$
$1.40 e-03$
$1.30 \mathrm{e}-03$
$1.20 \mathrm{e}-03$
1. $10 \mathrm{e}-03$
$1.00 \mathrm{e}-03$

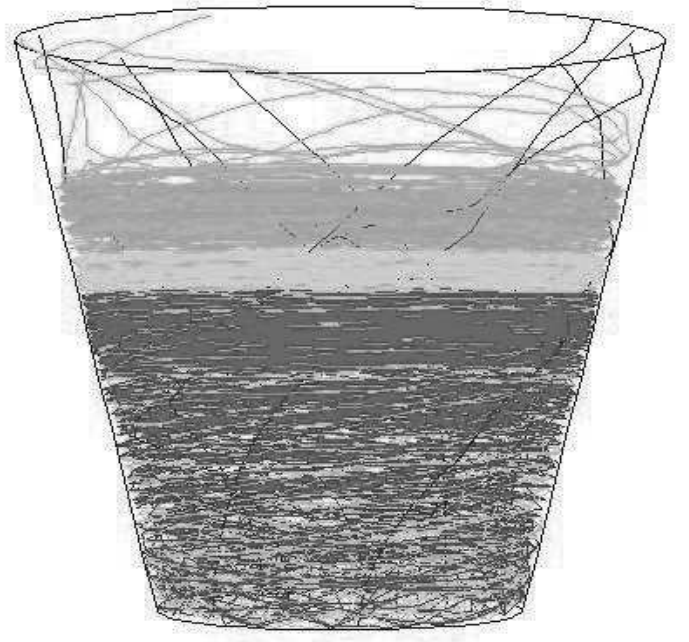

Particle Traces Colored by Particle Diameter $(\mathrm{m})$

ANSYS Fluent 15.0 (3d, pbns, rke)

Fig. 2 The trajectory of the polydisperse granules motion under the opening angle of the cone $13^{\circ}$ (the constrained motion of granules)

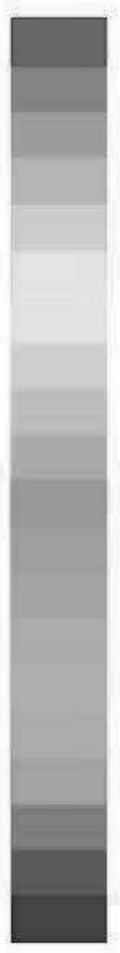
3. $00 \mathrm{e}-03$
2.90e-03
$2.80 e-03$
2.70e-03
$2.60 \mathrm{e}-03$
2. 50e-03
2.40e-03
2.30e-03
2.20e-03
2.10e-03
$2.00 e-03$
$1.90 e-03$
$1.80 e-03$
$1.70 \mathrm{e}-03$
$1.60 \mathrm{e}-03$
$1.50 \mathrm{e}-03$
$1.40 e-03$
1. $30 \mathrm{e}-03$
1.20e-03
1. $10 \mathrm{e}-03$
$1.00 \mathrm{e}-03$

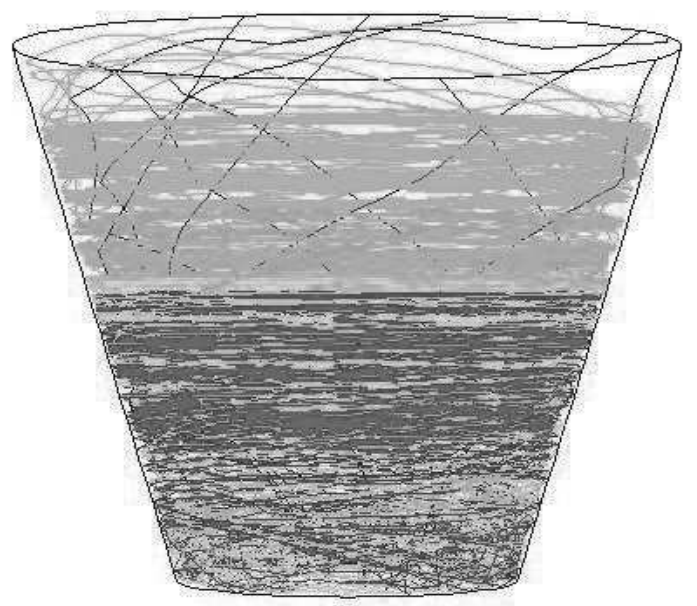

Particle Traces Colored by Particle Diameter ( $m$ )

ANSYS Fluent 15.0 (3d, pbns, rke)

Fig. 3 The trajectory of the polydisperse granules motion under the opening angle of the cone $16^{\circ}$ (the constrained motion of granules) 
The results of investigations confirm the crossing of trajectories of different fractions, determined in [11]. It has been found that the trajectory of the granules' motion in the constrained mode practically does not differ from the motion of granules with the same physico-chemical properties in the free motion, except the cases as follows: the presence of the polydisperse system at each height point of the workspace in the vortex granulator was additionally revealed. This leads to the stochastic change in the trajectory of the certain amount of granules of the main (at the estimated height) fraction in response to the collision with the granules of other fractions (the phenomenon is additionally displayed in Fig. 4).
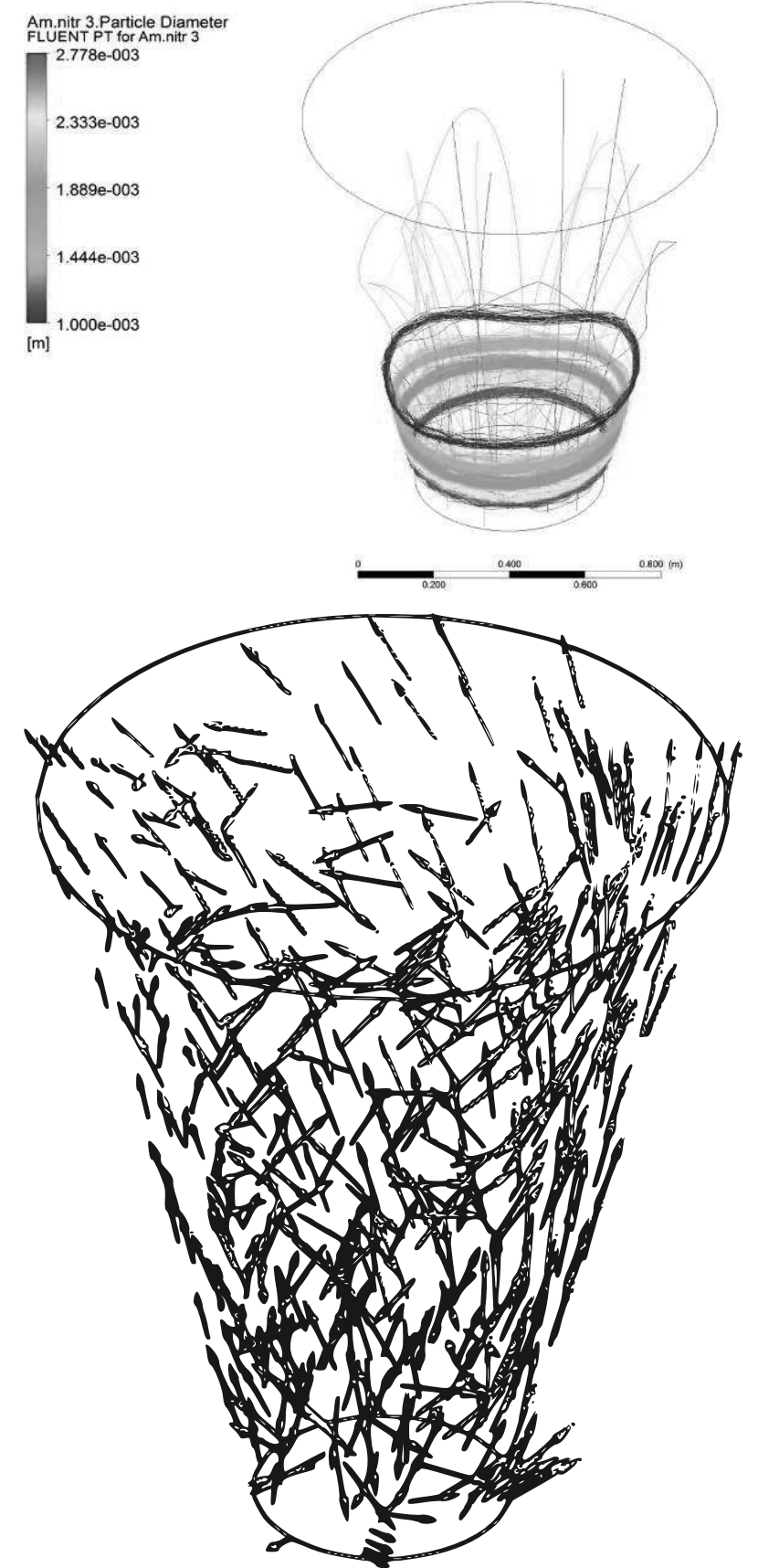

Fig. 4 The crossing trajectories of the polydisperse system of granules if the value of the opening angle of the cone is equal to $10^{\circ}$ (the constrained motion of granules)

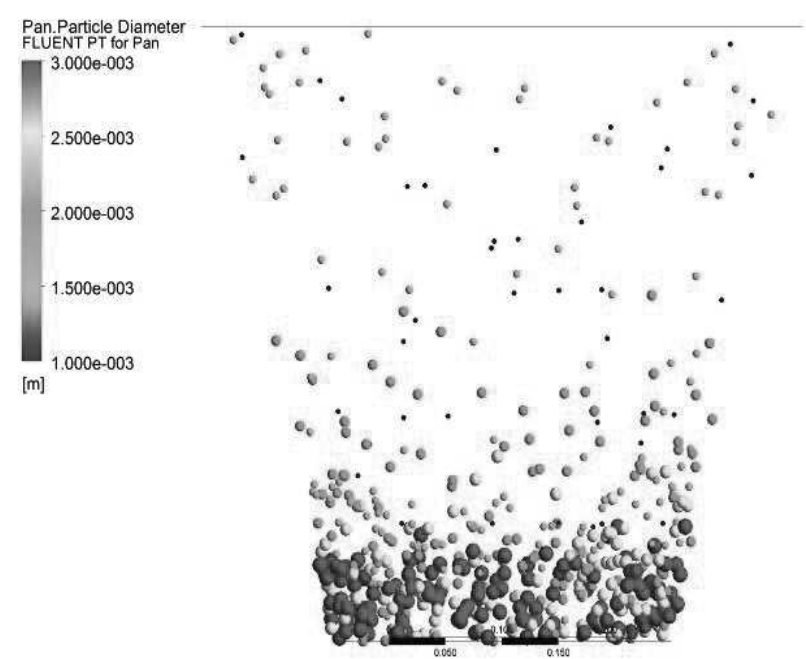

Fig. 5 The motion of the granules ensemble if the value of the opening angle of the cone is equal to $10^{\circ}$ (the constrained motion of granules) and $\psi=0.2$

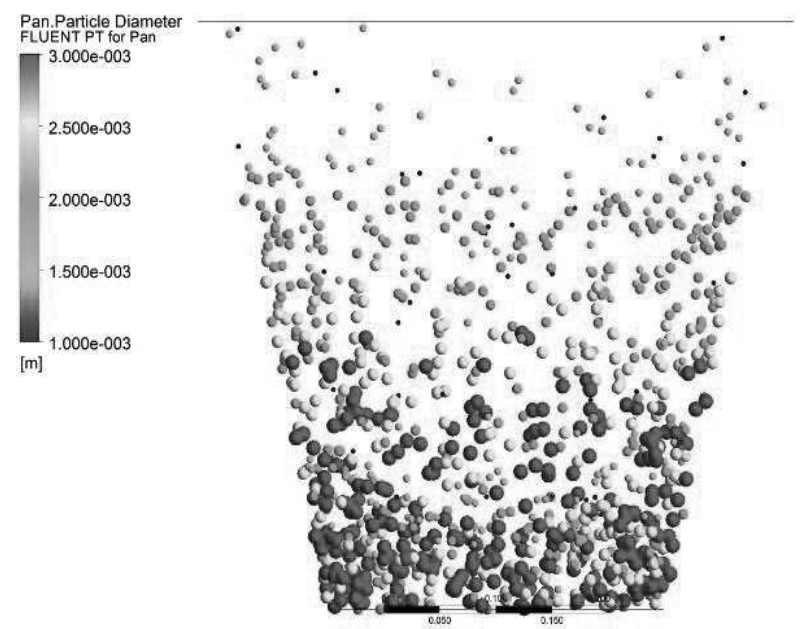

Fig. 6 The motion of the granules ensemble if the value of the opening angle of the cone is equal to $10^{\circ}$ (the constrained motion of granules) and $\psi=0.3$

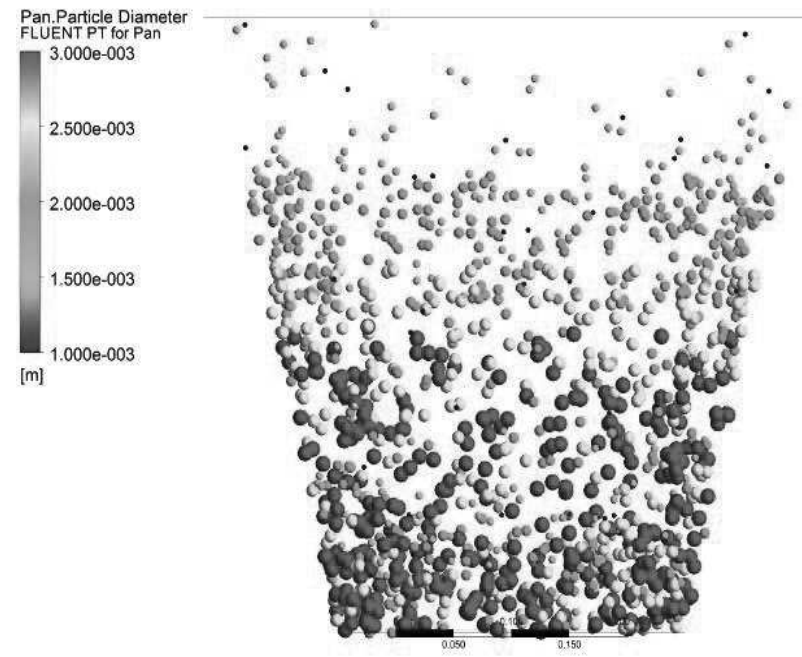

Fig. 7 The motion of the granules ensemble if the value of the opening angle of the cone is equal to $10^{\circ}$ (the constrained motion of granules) and $\psi=0.4$ 
The latter fact requires an additional continual description of the ensemble motion of granules of different sizes and their probable distribution within the workspace of the vortex granulator. To solve this task, an additional computer simulation with consideration of the constraint ratio of the granules' flow was carried out. The method, applied at this stage of investigations, enables us to enter the estimated number of granules of the defined size (an analogue of the fraction composition of the polydisperse system) and the total number of granules (an analogue of the constraint ratio of the disperse flow), taking into account the variable porosity of the vortex flow of the polydisperse phase within the height and the radius of the workspace of the granulator.

The results of the simulation of the particles ensemble motion in the range of the relative content of granules in the workspace $(\psi=0.2-0.4)$ are presented in Figs. $5-7$.

The further analogue simulation was carried out for the whole determined range of the opening angles of the cone $10-16^{\circ}$ and for taken as an optimal range $\psi=0.3-0.4$ in the blade-type swirlers.

Tab. 1 The results of the distribution of granules according to fractions in the ensemble under the condition of the constrained motion

\begin{tabular}{|c|c|c|c|c|}
\hline \multicolumn{5}{|c|}{$\psi=0.3$} \\
\hline \multirow[t]{2}{*}{$\begin{array}{l}\text { The fraction of granules in free mo- } \\
\text { tion: }\end{array}$} & \multicolumn{4}{|c|}{$\begin{array}{l}\text { The content }(\%) \text { of granules of the defined fraction in the workspace of } \\
\text { the granulator in the constrained mode of motion for the range of heights } \\
\text { of fractions in free motion }\end{array}$} \\
\hline & $<1 \mathrm{~mm}$ & $1-2 \mathrm{~mm}$ & $2-3 \mathrm{~mm}$ & $>3 \mathrm{~mm}$ \\
\hline$<1 \mathrm{~mm}$ & 90 & 6 & 4 & - \\
\hline $1-2 \mathrm{~mm}$ & 6 & 88 & 6 & - \\
\hline $2-3 \mathrm{~mm}$ & 4 & 10 & 84 & 2 \\
\hline$>3 \mathrm{~mm}$ & - & 8 & 10 & 82 \\
\hline \multicolumn{5}{|c|}{$\psi=0.4$} \\
\hline \multirow[t]{2}{*}{$\begin{array}{l}\text { The fraction of granules in free mo- } \\
\text { tion: }\end{array}$} & \multicolumn{4}{|c|}{$\begin{array}{l}\text { The content }(\%) \text { of granules of the defined fraction in the workspace of } \\
\text { the granulator in the constrained mode of motion for the range of heights } \\
\text { of fractions in free motion }\end{array}$} \\
\hline & $<1 \mathrm{~mm}$ & $1-2 \mathrm{~mm}$ & $2-3 \mathrm{~mm}$ & $>3 \mathrm{~mm}$ \\
\hline$<1 \mathrm{~mm}$ & 94 & 4 & 2 & 1 \\
\hline $1-2 \mathrm{~mm}$ & 5 & 92 & 3 & - \\
\hline $2-3 \mathrm{~mm}$ & 3 & 4 & 91 & 3 \\
\hline$>3 \mathrm{~mm}$ & 1 & 5 & 8 & 86 \\
\hline
\end{tabular}

The analysis of the results, presented in the table, allows us to conclude that:

- a growing constraint ratio of the flow extends the range of the fractions at the defined height;

- a growing constraint ratio of the flow increases the amount of the main (corresponding to the estimated height) fraction;

- the height of the vortex granulator decreases the fraction content from another range.

The results of investigations make it possible to determine the range for the values of $\mathrm{m}$ in each zone of the granulator (zone I of the vortex motion of granules, zone II of the combined upward and vortex motion of granules and zone III of the prevailing upward

$$
\sum \tau_{c m}=\tau_{c m}^{I}+\tau_{c m}^{I I}+\tau_{c m}^{I I I}=\tau^{I}\left(1-\psi^{I}\right)^{-m^{I}}+\tau^{I I}\left(1-\psi^{I I}\right)^{-m^{I I}}+\tau^{I I I}\left(1-\psi^{I I I}\right)^{-m^{I I I}}
$$

where the value of $\tau^{i}$ is found on the basis of solving the system of differential equations of the granule's motion, as shows in the work [9], and the value of $\psi^{i}$ motion of granules) according to the equation (2):

- Zone I - $m=1.7$ - 1.74;

- Zone II $-m=1.46-1.49$;

- $\quad$ Zone III $-m=1.1-1.13$.

The above-mentioned ranges for the average values of $\mathrm{m}$ contribute to the overall picture of the constrained motion of the polydisperse system, and they can be applied when determining the distribution laws of the granules in the workspace of the apparatus with a variable cross-section and the total "hydrodynamic" residence time of granules in the apparatus.

Thus, the total residence time of granules under the constrained motion is calculated according to the equation:

may vary during the computer simulation depending on the given conditions of the calculation. 


\section{Conclusion}

The results of the computer simulation are used in the separate block of the software Classification in vortex flow ${ }^{\mathcal{O}}[16]$ to calculate the distribution of granules according to fractions in the constrained motion under the condition that they change their mass due to dehydration. The automated calculation allows us to predict the behavior of the polydisperse system in its constrained motion in the workspace of the granulator with a variable cross-section area (Fig. 8).

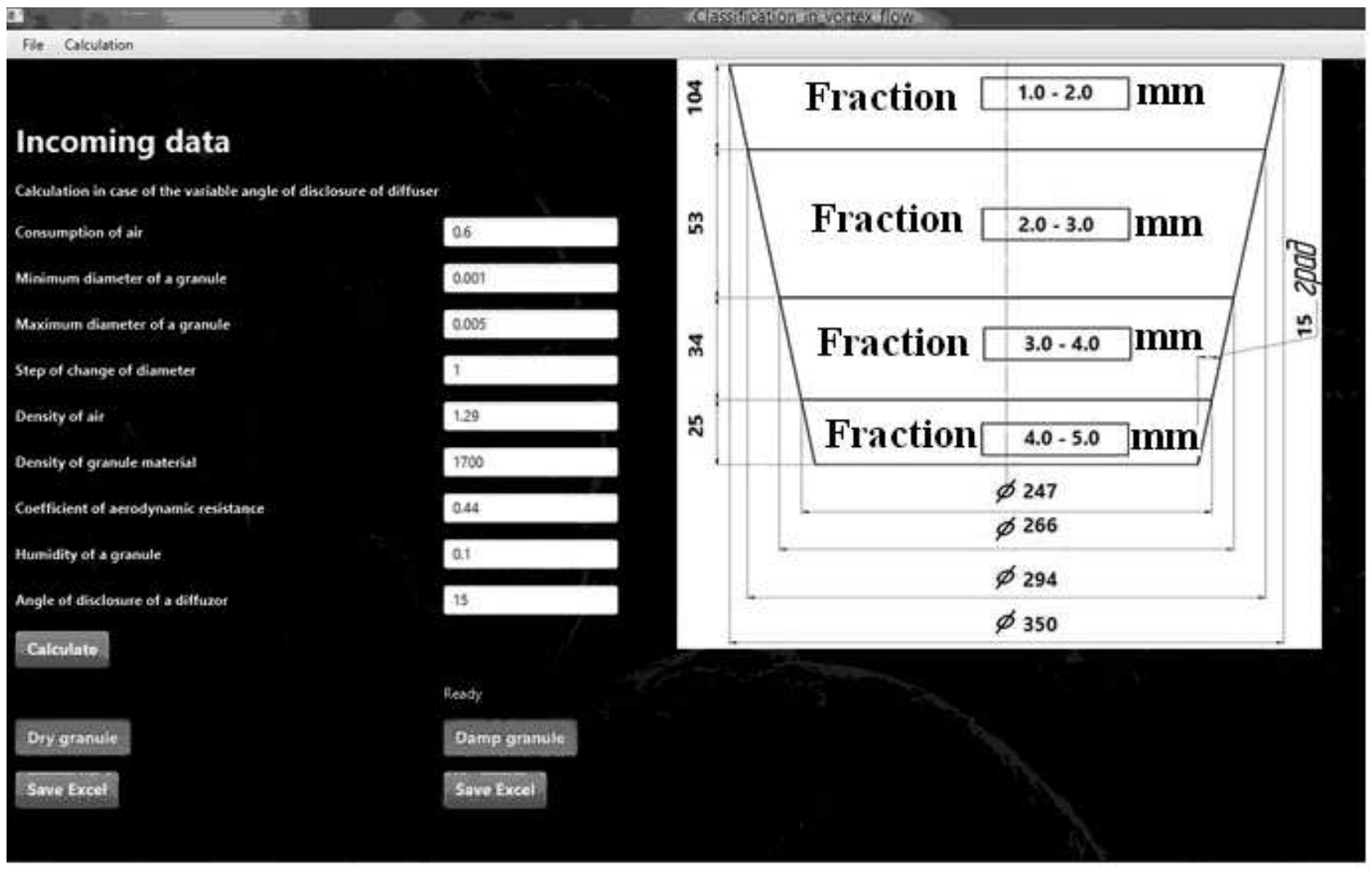

Fig. 8 Classification in vortex flow $(\mathrm{C}$ software

The data obtained are applied in the technological calculations of the heat and mass transfer (granulating in particular) equipment with the directional vortex motion of the disperse phase and its classification in the workspace of the apparatus.

\section{Acknowledgments}

This research work had been supported by the Cultural and Educational Grant Agency of the Slovak Republic (KEGA), project No. KEGA 002TnUAD-4/2019 and by the Ministry of Science and Education of Ukraine under the project "Small-scale energy-saving modules with the use of multifunctional devices with intensive hydrodynamics for the production, modification and encapsulation of granules", project No. 0119U100834.

\section{References}

[1] SINAISKI, E. G. (2010). Hydromechanics: theory and fundamentals. Weinheim, WILEY-VCH Verlag $\mathrm{GmbH} \& \mathrm{Co}$. KGaA.
[2] GIDASPOW, D. (1994). Multiphase flow and fluidization: continum and kinetic theory descriptions with applications. Academic Press, San Diego.

[3] HILTUNEN, K., JASBERG, A., KALLIO, S., KAREMA, H., KATAJA, M., KOPONEN, A., MANNINEN, M., TAIVASSALO, V. (2009). Multiphase Flow Dynamics: Theory and Numerics. VTT Technical Research Centre of Finland, Edita Prima Oy.

[4] MARCHISIO, D. L., FOX, R. O. (2013). Соmputational Models for Polydisperse Particulate and Multiphase Systems. Cambridge Series in Chemical Engineering. Cambridge University Press.

[5] CROWE, C. (2006). Multiphase flow handbook. Taylor \& Francis Group, Boca Raton.

[6] SOUKUP, J., KRMELA, J., KRMELOVÁ, V., SKOČILASOVÁ, B., ARTYUKHOV, A. (2019). FEM Model of Structure for Weightlifting in CrossFit in Terms of Material Parameters. In: Manufacturing Technology. Vol. 19, No. 2, pp. 321 326. ISSN 1213-2489. DOI: 
10.21062/ujep/290.2019/a/1213-

2489/MT/19/2/321

[7] SMETANKA, L., ŠŤASTNIAK, P. (2017). Analysis of Contact Stresses of Theoretical and Worn Profile by Using Computer Simulation. In: Manufacturing Technology. Vol. 17, No. 4, pp. 580 - 585. ISSN 1213-2489. DOI: 10.21062/ujep/x.2017/a/1213-

2489/MT/17/4/580

[8] KHANALI M., RAFIEE, S., JAFARI, A., BANISHARIF, A. (2012). Study of Residence Time Distribution of Rough Rice in a Plug Flow Fluid Bed Dryer. In: International Journal of Advanced Science and Technology, Vol. 48, pp. 103 $-114$.

[9] GOLDSCHMIDT, M. J. V., WEIJERS, G. G. C., BOEREFIJN, R., KUIPERS, J. A. M. (2003). Discrete element modelling of fluidised bed spray granulation. In: Powder Technology, Vol. 138 , pp. $39-45$.

[10] ARTYUKHOV, A. E., SKLABINSKYI, V. I. (2017). Investigation of the temperature field of coolant in the installations for obtaining 3D nanostructured porous surface layer on the granules of ammonium nitrate. In: Journal of Nano- and Electronic Physics, Vol. 9 No. 1, pp. 01015-1-01015-4.

https://doi.org/10.21272/jnep.9(1).01015.

[11] ARTYUKHOV, A. E., SKLABINSKYI, V. I. (2015). Hydrodynamics of gas flow in small- sized vortex granulators in the production of nitrogen fertilizers. In: Chemistry \& Chemical Technology, Vol. 9, No. 3, pp. 337 - 342.

[12] ARTYUKHOV, A. E., SKLABINSKYI, V. I. (2015). Theoretical analysis of granules movement hydrodynamics in the vortex granulators of ammonium nitrate and carbamide production. In: Chemistry \& chemical technology, Vol. 9, No. 2, pp. 175 - 180.

[13] ARTYUKHOV, A. E, OBODIAK, V. K, BOIKO, P. G., ROSSI, P. C. (2017). Computer modeling of hydrodynamic and heat-mass transfer processes in the vortex type granulation devices. In: CEUR Workshop Proceedings, Vol. 1844, pp. $33-47$.

[14] ARTYUKHOV, A. E. (2017). Internal recycled particles circulation in vortex granulator. In: Chemical and Petroleum Engineering, Vol. 53, No.7-8, pp. 423 - 429.

[15] ARTYUKHOV, A., IVANIIA, A., ARTYUKHOVA, N., GABRUSENOKS, J. (2017). Multilayer modified $\mathrm{NH}_{4} \mathrm{NO}_{3}$ granules with 3D nanoporous structure: effect of the heat treatment regime on the structure of macro- and mezopores. In: Proc. IEEE International Young Scientists Forum on Applied Physics and Engineering (YSF-2017), pp. 315-318.

[16] Certificate of copyright registration No. 67472 UA (2016). Computer program "Classification in vortex flow". 